\title{
ADIR Smart Coaching System
}

\author{
Misun Hong ${ }^{1}$, Jung Hwan Park ${ }^{1, *}$, Jungwon $\mathrm{Cho}^{2}$ and Kyoung Hoon Lew ${ }^{3}$ \\ ${ }^{1}$ Department of Education, Jeju National University, \\ 102 Jejudaehakno, Jeju-si, Jeju-do, S.Korea \\ ${ }^{2}$ Department of Computer Education, Jeju National University, \\ ${ }^{3}$ Graduate School of Education, SoongSil University, \\ 369 Sangdoro, Dongjakgu, Seoul, S.Korea \\ hms0510@daum.net,edu114@jejunu.ac.kr,jwcho@jejunu.ac.kr,lewkh@ssu.ac.kr
}

\begin{abstract}
People usually collect information and solve problems Aunder smart environments nowadays. The abilities of individuals required in this smart time are creative and active thinking. In that point, the concept of coaching which can draw the potentials of receivers and help to internalize their problems has been nagnified in various fields. If you have looked at researches of coaching until now, researches about the contents of coaching course, learning, and management coaching has been done a lot. However, studies of the environments in which coaching is berformed cre not sufficient except the sports field. In order to maximize the success rate of coaching, elaboration of the contents is also important, but the discussions about the environments where coaching are carried out are also necessary. As smart devices and various digital equipment are activated, studies are required on what technical and environmental aspects of these have an impact on coaching.

Therefore, this study proposes an ADIR(Analysis, Design, Implementation, Reflection) smart coaching system where teaching is carried out in smart environments, by combining with the smart and coaching which are new paradigm concepts of future society. This study has designed a coaching system that is composed of four modules, 'Analysis, Design, Implementation, and Reflection' and 8 stages by each module. Especially, smart coaching will be able to maximize the efficiency of coaching by overcoming the limitations of time and space and distinguishing computer programs and coaches do. In addition, within the smart coaching system, there are various coaching systems such as personal coaching, group coaching, and professional coaching, and so on. And, it will make multidimensional approach possible which cannot be done in face-to-face instruction. Furthermore, in the future researches individualized and professional smart coaching system studies should be contmued by constructing systems corresponding to various contents.
\end{abstract}

Keywords: Smart coaching, ADIR Smart coaching system, ADIR Smart coaching model

\section{Introduction}

\subsection{Purpose and need for this research}

The future society is possibly expected to evolve into "a new knowledge-based

* Corresponding author. 
society" with a focus on activities and integration of knowledge [1]. In addition, the wide spread of smart devices and full-fledged information society have led to major shifts of paradigm of society as a whole. The creation of new value is depicted with the construction of smart environments at the fields of info-communications, industry, management, and education, different from stereotypes of the tradition. Now, the world has become a smart era. The term 'smart' is a word with meanings such as "neat, smart, and sophisticated" originally. It is named as a mixture of "self-directed, motivated, adaptive, resource enriched, and technology embedded' [2]. It is not easy to specifically define smartness, focused on not the innovation of technology itself, but personal experience (User experience, UX), and it is clear that smartness has contributed to the paradigm shifts of society as a whole [3]. Human resources required for the smart society are someone who has the ability of reflection and creative problem recognition. According to the National Information Society Agency, [4], the four conditions of human resources in the future are 'creativity, self-leadership, interpersonal relations, and critical thinking'. That is, those require creative bumans. To be like them, individuals must be active and have critical thoughts. Therefore, they must have a sense of responsibility for their actions. In addition, It will be needed to understand knowledge contextually for problem solving and to spread the values through collaboration. This is the smart thinking. These smart thinking has changed patterns and communication characteristics of people. We can say that our lives are achieved through other people's lives, and this time's connections are communications, and also the thing that can execute communications effectively is media[5]. Through smart technology, communications each other are possible, information can be shared, and values can be created. It is a erathat individuals and enormous groups can live together. During these processes, personals' own values can be established and they can do problem solving activities Coaching is a process to maximize receivers' growth while coaches communicate with receivers to find answers receivers themselves, based on expectations of individuals' potential capabilities [6]. To the receivers, in terms of showing more their confidences relatively, better communication skills, and enhancing achievement rate of goals, there are educational meanings of the coaching [7]. Coaching is a process to support the activities of problem solving, and coaches and receivers form cooperative relationships through action-oriented partnerships. Coaching like this is a process, kind of leaning and developing [8-11]. However, the situation is that academic researches of coaching are very lacking in terms of both quantity and quality, empirical studies of coaching are more lacking about whether goals really create effects [11-14]. Namely, it is a time that model studies of the effects of coaching and studies of the effectiveness are required. Also, because the coaching environments are mostly carried out face-to-face or on-line, they become restricted by time and space. So, we need the coaching environments that can be done whenever one wants coaching at any time, and anywhere. The combinations of smart environments using various methods, a system for analysis, design, and reflection of coaching are required.

This study proposes a smart coaching system where teaching is carried out in smart environments, by combining with the smart and the coaching which are new paradigm concepts of future society. Further, it attempts to implement overall system to solve problems of diverse contents, based on the process of coaching to help smart thinking under the smart environments. 


\section{Theoretical Background}

\subsection{Definition and analysis of the concept of smart coaching}

To analyze the concept of smart coaching, it is necessary to establish the concepts of coaching and the smart. First, the word 'smart' is friendly and close to modern people. Ranging from smart devices such as smartphone, smart-tab, and smart TV to smart advertising and smart learning, the smart has become a part of our lives now. However, it is difficult for everyone to define the smart if they explain it. This is because the meanings of the concept of smart are usually used in different ways respectively. In the media field, it means connectivity and compatibility between devices [15]. In the education field, smart is stood out to be intelligent, customized, and self-priven [16]. Also, as abundant and accurate information promptly came to be acquired, it is also named as "smart consumption" like consumption pattern that comprehensively considers price, quality, and whether to be eco-friendly. Like this smart is used in various fields having different meanings. It is the concept of the ney paradigm caused by the Internet revolution and the spread of the intelligent equipment. If we see the features of smart, "The characteristics of smart learning are using of smart devices and intelligent, conative, and individualized tailor made learning." were said by M. Son [17]. J. Park, J. Cho, and H. Kim [18] sa d that U-learning's features are flexibility of space-time, flexibility of knowledge, maximization of interactions, individualization, diversity, invisible environments. C.ace and J. Jong [19], as the characteristics of the smart media for smart environmental anstysis, refer to ubiquity, accessibility, connectivity, location which ean connect with the Internet anywhere at any time. In this study, saying 'smart' is defined as the environment to enhance communications with human to human and media to human through mobility, connectivity, intelligence which smart media give.

Second, we try to organize a concept of coaching. Thomas Leonard, financial architect in 1980 started coaching personally, and the form of the modern coaching has been started. Etymology of coaching is derived from the carriage which was developed by a city, Kocsi of Hungarl in the 15th century. They began to use the word 'coach' as alias of tutor in the $\mathrm{UK}$ in $1840 \mathrm{~s}$. As passengers riding a horse-drawn carriage go to their destinations, the term came to be used as students arrived to their destinations under the coaching of teachers [20]. Then, it was applied to sports, and coaching was utilized for improvement of duties of employees in the field of business management from 1950s $[2$ \%. Since then, the coaching was looked at as integrated means connecting diverse cultures with the launch of the Euro in order to open up a new era of integration in Earope in the 21 st century. Now, it has been discussed in various fields such as family science, education as well as psychology, and business administration. The core of coaching is "communication". It is an effective means to form integration while interacting and colliding in relationships between human to human, media to human, and human to environment. Coaches and receivers have cooperative relationships through the action-oriented partnerships. Coaches try to derive answers from the receivers rather than present their own answers. Coaches can make achievement and creative problem solving through dialogue processes to find the strengths of the counterparts and to realize them. According to International Coach Federation, coaching is professional and continuous relationships which support to achieve excellent results in lives, careers, businesses, and organizations [22]. Coach Federation Korea Coach Association said that coaching is a horizontal partnership to help to achieve the best value with the full potentials of individuals and companies [20]. If we 
summarize this comprehensively in this study, coaching is a course that provides us with necessary knowledge, opportunity, and means for individuals to be more effective and grow. I awaken the potential of each person. Coaching is cognitive and behavioral communications and activity processes that receivers can set their own goals in the cooperation with coaches and themselves, to maximize the potentials of individuals. The concept of smart coaching has never been defined officially. We try to define that on the basis of 'smart' and coaching that have brought changes like the new paradigm of smart era. "Smart coaching is a problem-solving process to develop the characteristics of smart communication" And, the smart communication referred can be thought as 3 things. The first is mobility. It is an extended meaning that is beyond the previous concept of mobility because it can equip the ubiquity that can move space to space beyond the space limitations [23]. The second is connectivity. It means a state which can universally interact people to information, individual to indivídual, and individual to group online and offline. It has social coonnectivity, informational connectivity, and technical connectivity. The third is intelligence. It can be provided dynamic information and utilize that, depending on the location and characteristics of individuals. That is, there is an advantage that can provide a method for grasping the characteristics of individuals and can solve problems fitting to them and make the processes as portfolios.

Taken together, smart coaching in this tudy can be referred to "smart-type problem solving processes that vitalize mobility connectivity, intelligence, and smart coaching is also a strengthening method of communication realizing personal goals by making cooperative relations between physical smam environments and face-to-face online coaching."

\subsection{Navigation of smartcoaching system model}

It is necessary to nayigate the process of coaching for implementation of smart coaching. Coaching 15 a process to help to find resolutions of currently facing problems of their own based on structured processes, through stimulating ideas of the individuals, expanding thoughts, and recognizing them newly. There is no standardized process or definition, but researchers pursue specific processes with operational definitions respectively. And, if previous studies are arranged, standardization of goals, recognition of reality, navigation of alternatives, plan of action program, and the finishing stage can be gone through [20, 24, 25]. In this study, based on the model of coaching, it is intended to present a smart coaching system model. The stages of the standardization of goals and the recognition of reality are planned to be an analysis module, the stage of navigation of alternatives is to a design module, the stages of establishment of implementation plan and confirmation of will are to an implementation module, and the finishing stage is to be a reflection module. Taken together, we would like to propose the ADIR smart coaching system model that is composed of 4 modules and 8 stages. Model ADIR smart coaching system is consisted of four modules such as 'Analysis, Design, Implementation, and Reflection'. The Analysis module aims to clarify problems and enhance motivation through self-analysis and focusing. This will do data of all materials and recognize problems of receivers; self-analysis for problem solving will be organized. At this stage smart match is different from the face to face coaching. Receivers come to meet coaches through normal matching; going through the two stages they can meet desired coaches through questionnaires about the desired coaches. The following is a design module. It is the stage to create an implementation map by looking for specific measures through the navigation of alternatives and plan of action 
program. Information is to be collected by presenting various options through experts' advice and use of smart devices. In the second stage, formulate an implementation plan and create long and short term plan table, implementation map is to come out eventually. Third step is implementation module. It is a step that must take advantage of smart environments and should be activated. Navigate the alternatives which were found in the plan module, and select the alternative you need to change firstly and plan something specifically, setting the time. Then, select the alternative of implementation, and personal implementation and group implementation are distinguished based on whether personal implementation is done. Implementation module is a stage that smart communications are activated, and receivers should work actively at this stage. The last is the reflection module. The reason why this module uses reflection, not evalyation module is that coaching is a reflection process through reflective thinking eventually. During this process, changed yourself are recognized by switching the viewpoint of the problem. The reflection module will be integrated with analysis report, implementation map that will made at analysis, design, and implementation module. Those data will be used as reflection materials to be portfolios and stored on smart coaching DB. Digitize the results before the stage to collect the results for opportunity of self-reflection. This can be achieved as convenience of storage usage of sharing, and simultaneity of evaluation [26]. These all courses are presented with tailor-made portfolios that are customized to the user [27]. Evaluation report will be created through the portfolios' reflection and receivers' reflection eyentually. It ril be decided to go to the analysis module again or end the coaching, depending on whether the last is completed.

\section{ADIR Smart Coaching System •}

Design structure diagram of the ADIR smart coaching system is like Figure 1.

We want a brief description of the smart coaching of the whole processes. With the start of coaching, the smart coaching system comes into. The receivers will enter the analysis module, ând do checklists and relevant tests to solve problems. Then, they are asked questions related with matching. When those reach the matching rate, they come to do the smart matching with) their desired coaches. The design module helps to be able to find alternatives bycxperts in various fields and helps to utilize smart devices online. The implementation module takes advantage of features of the application using smartphones to facilitate connectivity and mobility to enhance the practical abilities of behavioral changes. It is possible to evaluate and inspect them through the maintenance and alarm function. It also creates a group that is making the same goal, and it will do group inspections and evaluations in the smart environments. At the last module, with data from each module, they make portfolios and come to do the checklists to reflect on recervers themselves. In this process, when the execution rate has reached the expected value, that will be finished. However, if they do not reach the target, they go to the analysis module and analyze and evaluate the insufficient reasons. 


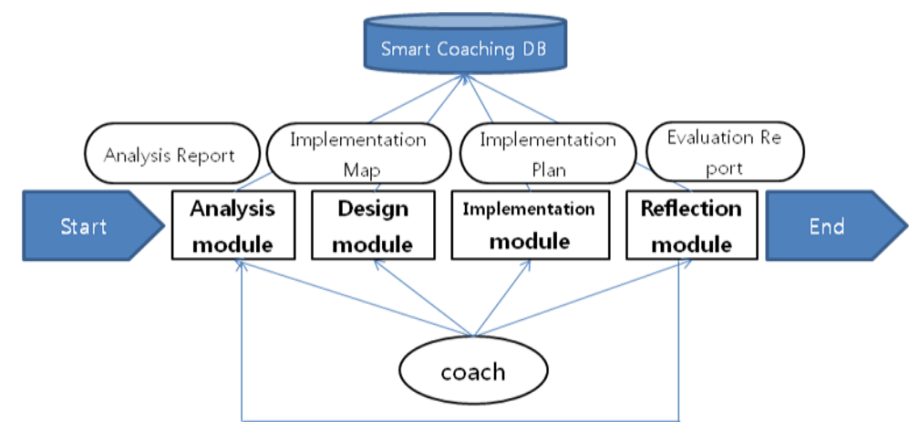

Figure 1. ADIR smart coaching system

\subsection{Analysis module}

Analysis module of the ADIR smart coaching system is like Figu e 2. Simultaneously with the start coaching, the analysis module will come. In this module, focusing and process of self-analysis are realized. Focusing is a stage to recognize problems which receivers have and discover the possibilities whether to adjust themselves. It is possible to increase leading thoughts and responsibilities for the problems in this procedure. The key to focusing is the question process of clarification.

Second stage of the analysis module is self-analysis. It is the stage of analyzing the problems found through the focusing. Ot is the stage of analyzing themselves by selfobservation, relevant inspection, and matching related inspection to find their current situations. Tests for all analyses ontine will be performed because related inspections have been programmed entirely. All analyses are performed on-line in the module; it will produce the result of 4 Analysis Reports of analyses of the required resources) and the current state of receivers' problems. These results will be used at the design module and implementation module; they can be the materials to represent the coaching effects through the comparison with preliminary tests and post-tests, Smart matching is done through this process. In face-to-face coaching, it is difficult for receivers to be matched with desired coaches stochastically. However, smart match is able to supplement that point; the receivers can be matched with coaches who they want. Computer program can find matching relevant tests and coaches who are higher in matching rate statistically. We clarify the variable factors that affect the matching, and choose important considerations which the receivers think valuably. Variable factors selected can be given discriminatory scores, and the coach who variable factors match the highest is searched.
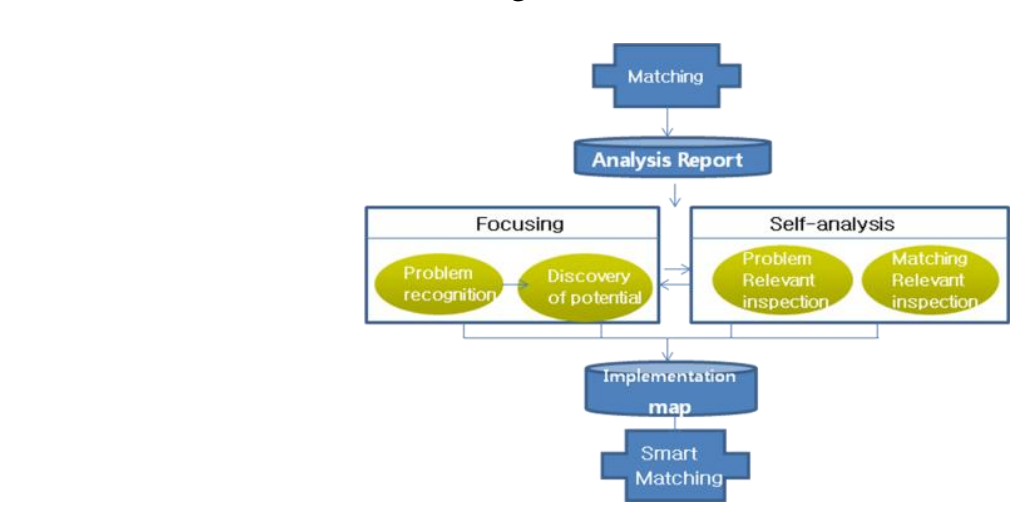

Figure 2. Analysis module system 


\subsection{Design module}

Design module of the ADIR smart coaching system is like Figure 3.

It is a design module to navigate alternatives, to develop an implementation plan. The first step of the module is the process of searching for alternatives to get through the experts' advice and data collection utilizing the smart devices. Smart searching features and face-to-face coaching are carried out at the same time. You navigate as many alternatives as possible to explore why you did not look for and apply to alternatives until now. At this time, consulting with experts in each field is conducted, and the solutions are stored in the data of design module again. Further, in the state of each alternative being displayed, questions for specific implementation plans are shown, those are saved onto the <Implementation map> automatically during this process. The output from the design module is <Implementation map>. The implementation map is the achievement that short and long term implementation plans of receivers are connected each other like a map. Complete execution strategy for alternatives is raised and order of priority is determined. Also, implementation period, implementation amount, and evaluation method for implementation are recorded in detail.

\subsection{Implementation modue}

Implementation module of the ADIR smart coaching system is like Figure 4.

The implementation module is a step that smart environments can be taken advantage of mostly. The data Implementation map > which came out as a result of the design module are analyzed, select a concrete implementation alternative. It is possible to use smart taps or smartphones that are high in mobility and portability, and remarkable processing functions and alarms can be done using these. Practice rate is recorded; the evaluation value of each individual user is saved and their goals will be helped to achieve. And, a conversation forum is also provided by collecting groups to set the same goal and try to practice that. Information is shared each other and they help to check the execution, and group coaches can have the role to help them together in the process. Rather than man-to-man coaching, group coaching is done. In the process, the receivers will share ideas and various implementation methods. 


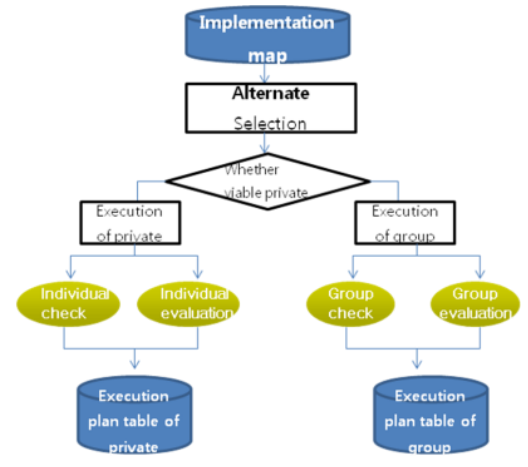

Figure 4. Implementation module system

\subsection{Reflection module}

Reflection module of the ADIR smart coaching system ís like Figure 5.

The last is the reflection module. <Smart coaching DB> refers to a material that aggregated and analyzed the <Analysis report> of analysis module, <Implementation map> of the design module, and < Implementation plan table> of the implementation module. At the stage of portfolio reflection, whether the power of implementation increased is checked through a smart coaching DB and statistics values come out to check whether the target value determined by the implementation plan table has achieved. Then, introspective reflection for the subjective growth and change is done through the coaches and reedivers reflection. After that, they determine whether to continue the implementation. If they want the coaching continually, they come to decide a module based on the analysis of the smart coaching DB. The analysis module, the design module, and the implementation can be divided according to the determination of the module. If they do not need the continual coaching, it is possible to be in the reflection module on determine the coaching end.

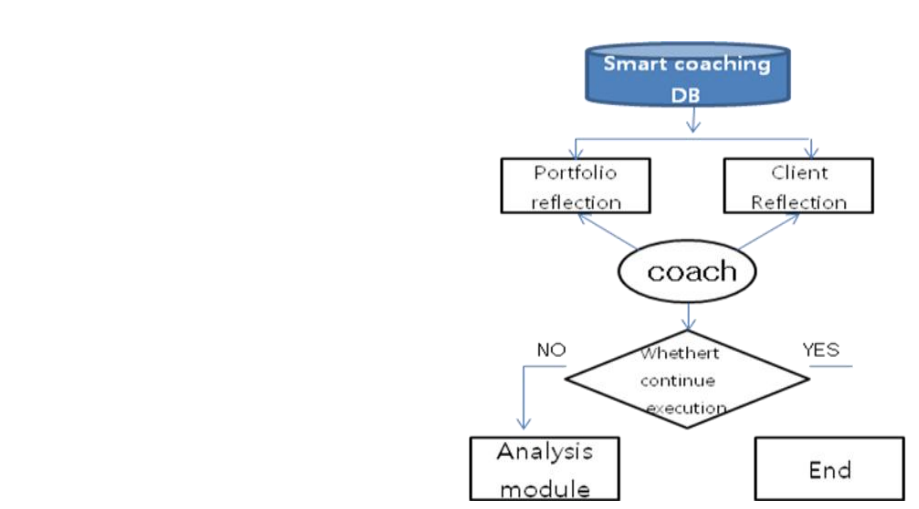

Figure 5. Reflection module system

\section{System implementation}

The design of the ADIR smart coaching system that is proposed in this study is compared with the environments of previous coaching, and discussion of the realization is shown at Table 1. In summary, features of smart environments such as automaticity, intelligence, connection can be realized different from the previous coaching. Therefore, materials and data of every coaching are saved, and browsing is possible without time 
and space constraints. In addition, there is a function to check the implementation rate and self-inspection. If these are organized, smart coaching is an intelligent system and efficient process that make the most of the characteristics of the receivers.

\section{Table 1. ADIR smart coaching and comparison of existing>}

\begin{tabular}{|c|c|c|}
\hline general Coaching & \multirow{4}{*}{ Module } & smart Coaching \\
\hline $\begin{array}{l}\text { idendify: The process of setting goals } \\
\text { with a challenge and subject of debate of } \\
\text { coaching }\end{array}$ & & $\begin{array}{l}\text { idendify: The process of setting goals } \\
\text { with a challenge and subject of debate of } \\
\text { coaching }\end{array}$ \\
\hline $\begin{array}{l}\text { detailed: detailed and Stage setting } \\
\text { goals to ensure }\end{array}$ & & $\begin{array}{l}\text { - detailed: detailed and Stagesetting goals } \\
\text { to ensure }\end{array}$ \\
\hline $\begin{array}{l}\text { Self-analysis : Step of analysis and } \\
\text { allow the difference between the actual } \\
\text { and target }\end{array}$ & & $\begin{array}{l}\text { - Self-anafysis : Step of analysis and allow } \\
\text { the difference between the actual and target }\end{array}$ \\
\hline - Automatism : Not applicable & \multirow[t]{2}{*}{ Analysis } & $\begin{array}{l}\text { Automatism:Smart match is performed. } \\
\text { And decided to find statistically coaching } \\
\text { high concordance rate of matching relevant } \\
\text { inspection }\end{array}$ \\
\hline - Intelligence : Not applicable & & $\begin{array}{l}\text { Intelligence : Data and analysis of } \\
\text { individual receive more personalized to the } \\
\text { client is performed }\end{array}$ \\
\hline
\end{tabular}

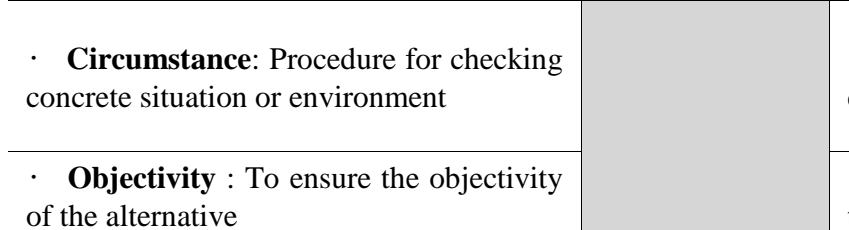

Circumstance: Procedure for checking concrete situation or environment

Objectivity : To ensure the objectivity of the alternative

- Expertise : Find the publications and expert advice

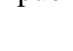

- Concurrency: Not applicable

Expertise : Find the publications and expert advice

\section{$y$

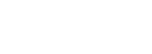 \\ - Connectivity : Not applicable}

Connectivity : Information collected through the connection of social infrastructure between connectivity and data

- Self-check : Action planning stage for the execution plan

Environmental support : Support of Implementation

Concurrency : Smart search function and face-to-face coaching is carried out at the same time

the surrounding environment

Self-check : Action planning stage for the execution plan

Environmental support : Support of the surrounding environment 


\begin{tabular}{|c|c|c|}
\hline · Mobility : Not applicable & & $\begin{array}{l}\text { - Mobility : Move and enhancements carry } \\
\text { smart device }\end{array}$ \\
\hline - Connectivity : Not applicable & & $\begin{array}{l}\text { Connectivity : It will be performed } \\
\text { intelligently inspection procedure required to } \\
\text { perform the retrieval of data, such as alarms } \\
\text { and }\end{array}$ \\
\hline $\begin{array}{l}\text { Critical Thinking: The thought } \\
\text { process and critical analysis to be } \\
\text { complementary to that it went well }\end{array}$ & \multirow{4}{*}{ Reflection } & $\begin{array}{l}\text { Critical Thinking: The thought process } \\
\text { and critical analysis to be complementary to } \\
\text { that it went well }\end{array}$ \\
\hline $\begin{array}{l}\text { Integrative thinking: Procedure to } \\
\text { analyze the steps of coaching overall and } \\
\text { Overall }\end{array}$ & & $\begin{array}{l}\text { Integrative thinking: Procedure to } \\
\text { analyze the steps of coaching overall and } \\
\text { Overall }\end{array}$ \\
\hline - Automatism : Not applicable & & ialysis of \\
\hline - Intelligence : Not applicable & & Intelligence: We enables you to select \\
\hline
\end{tabular}

\section{Conclusion}

Studies of the environment in which coaching performed is not in a sufficient situation except the sports field. Thorder to maximize the success rate of coaching, elaboration of the coaching contents is also important, but the discussion about the environments where coaching is carried out is also necessary. So, the design of the smart coaching system, willachieve)eficient environments as coaching environments are extended more than the online video or face to face. Especially, it is possible to overcome the time and space limitations, and it will be divided like that the things which coache do and the field which computer programs deal with. Thus, it is expected that minute inspections which only people can do and accurate information processing of computer can be done at the same time. In this regard, the construction of more efficient and intelligent smart coaching system than the conventional coaching is required.

On the other hand, smart coaching researches to strengthen communications between coaches as well as coaches and receivers, are needed in the future. Namely, it is expected to be able to build a super vision system that coaches reflect each other and grow further while doing feedback. It is also expected that since fragmented and assortatively professional smart coaching system could be constructed, various helpful studies can be done.

\section{References}

[1] National Information Society Agency, "IT-enabled strategy and prospects for change in the future of smart era", (2012).

[2] Ministry of Education of Korea, "Smart Education Implementation Strategy", (2011).

[3] S. Myeong, "Paradigm shift and the concept of e-government Gov3.0-based smart social conversion", korea Society policy Spring Academic Papers Collection, (2012), pp. 325-341.

[4] National Information Society Agency, "ICT strategy and outlook of the paradigm shift in the smart 
era", (2010).

[5] C. Moon, et al., "Prospect of u-Learning based on consilience communication aspect between humans and media", Korea Academia-Industrial cooperation Society Fall Academic Papers Collection, (2010), pp. 700-703.

[6] H. Na, "Development of Physician Coaching Model for Improvement of Patient-Doctor", the Korea Contents Association, vol. 13, no. 2, (2012), pp. 331-340, http://dx.doi.org/10.5392/JKCA.2013.13.02.331.

[7] H. Shin, "Coaching Rhetoric in Communication Education - With Operation Cases of Leadership and Communication Course", Korean Joural of Rhetoric, vol. 15, no. 1, (2011), pp. 215-261.

[8] R. C. Diedrich, "An Iterative Approach to Executive Coaching", Consulting Psychology journal: practice and Research, vol. 48, no. 1, (1996), pp. 61-66, http://dx.doi.org/10.1037/1061-4087.48.2.61.

[9] D. T. Hall, K. L. Otazo and G. P. Hallenbeck, "Behind closed doors: What really happens in executive coaching", Organizational Dynamics, vol. 27, no. 3, (1990), pp. 39-58, http://dx.doi.org/10.1016/S0090-2616(99)90020-7.

[10]j. Sherin and L. Caiger, "Rational-emotive behavior therapy: A behavioral change model for executive coaching?", Consulting Psychology Journal: Prectice and Research, vol. 56, no. 1, (2004), pp. 225-233, http://dx.doi.org/10.1037/1065-9293.56.4.225.

[11] S. Lee, "A Literature Review and Future Research Directions of Deadership Coaching”, Journal of Institute for Social Sciences, vol. 20, no. 1, (2009), pp. 115-142.

[12] R. G. Hamlin, A. d. Ellinger and R. S. Beattie, "coaching at the Heart of Managerial Effectiveness: A Cross-cultural study of Managerial Behavior", Human Resource Development International, vol. 9, no. 3, (2006), pp. 305-331, http://dx.doi.org/10.1080/13678860600893524.

[13] D. Mackie, "Evaluating the Effectiveness of Executive Coaching. Where Are We Now and Where Do We Need To Be?", Australian Psychologist, vol. 9, Nno. 3, (2006), pp. 305-331, http://dx.doi.org/10.1080/00050060701648217

[14] S. Cho, "Development of Coaching Program for Coaching teffect Research", Korean Association of Human Resource Development, vol. 13, no. 1, (2010), pp. 27-74.

[15] G. Winslow, "Tablet and Smart TV/: What You Need to Know", Broadcasting \& Cable, http://www.broadcastingcable.com/article/462487Tabrets_and_Smart_TVs_What_You_Need_to_Kno w.php.

[16] G. No, S. Ju and J. Jung, An) Exploratory Study on Concept and Realization Conditions of Smart Learning", International Conference on Digital Policy \& Management, vol. 9, no. 2, (2011), pp. 7988.

[17] M. Son, "Analysis of Awareness of Educational Content and Actual Conditions of its Use in a Smart Learning Enyironment", Kyung oo Ndtional Univ. Graduate School of Education, (2012).

[18] J. Park, J. Cho and H. Kim, "(Easy to understand) U-Learning", Hajisa, (2007).

[19] C. Lee and Jong, "Consideration for cognitive effects in smart environments for effective UXD(User eXperience Design)", International Conference on Digital Policy \& Management, vol. 11, no. 2, (2013), pp. 397-405.

[20] http://www. kcoach.or.kr, Korea Coach Association.

[21] R. D. Evered and J. C. Selman, "Coaching and the art of management. organizational Dynamics", vol. 18, no. 2, (1989), pp. 16-32, http://dx.doi.org/10.1016/0090-2616(89)90040-5.

[22] www.coachsedepation.org, International Coach Federatoin.

[23] H. Park A Study of Using DMB \& Its Sociocultural Implications: Focusing on the Changing Pattens of Media Consumption \& Micro-Coordination in Daily Culture", Korea Regional Communication Research Association, vol. 8, no. 1, (2008), pp. 121-160.

[24] htp://www.incoaching.com, Incoaching Center.

[25] http://www.asiacoach.co.kr, ASIA coach Center.

[26] J. Park, "A Design of Digital Portfolio Assessment System in Ubiquitous Computing”, Korea Academia-Industrial cooperation Society, vol. 9, no. 1, (2005), pp. 214-220, http://dx.doi.org/10.5762/KAIS.2008.9.1.214.

[27] J. Park and C. Moon, "Design and Development of a Teaching Assessment System for Improving Teaching Skill in u-Campus", Korea Academia-Industrial cooperation Society, vol. 12, no. 5, (2011), pp. 2124-2132, http://dx.doi.org/10.5762/KAIS.2011.12.5.2124. 


\section{Authors}

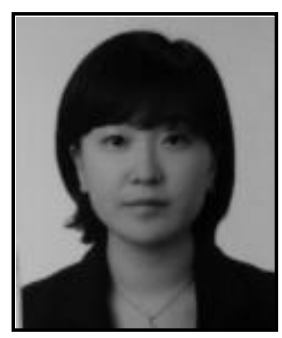

\section{Misun Hong}

She received B.A. degree in law from Jeju National University in korea in 2003, and M.A. degree in Counseling Psychology from Jeju National University in korea in 2009. She studying a Ed.D in Educational Techology in Jeju National University now.

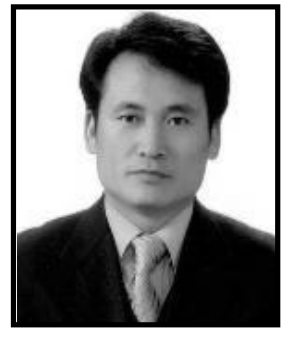

\section{Junghwan Park}

$\mathrm{He}$ received B.A. degree in Education from Wonkwang University in Korea in 1992, and MA. degree in Educational Psychology from Wonkwang University in 1994, \& Ed. D degree in Educational Techology from Korea /National University of Education, in Korea in 2001. He is a professor at Jeju National University, Graduate School of Education

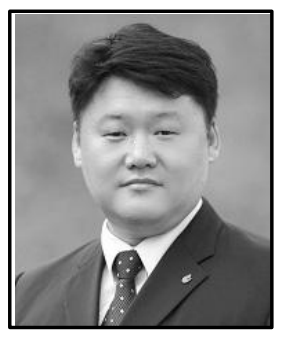

\section{Jungwon Qho}

He received the B.S. degree in Information \& Telecommunication Engineering from University of Incheon, Incheon, S.Korea at 1996, and earned the M.S. and Ph.D. degrees in Electronic Communication Engineering from Hanyang University, Seoul, S.Korea at 1998 and 2004, respectively. In 2004 , he joined Jeju National University, Jeju, S.Korea, where he currently is a Professor at the Department of Computer Education. He was Vice-dean at the College of Education at 2011 and 2012. He also visited the Purdue University as a Visiting Scholar in 20072008 . He is an author of over 35 papers in refereed international ournals and conference proceedings. His research interests include computer education, information ethics, smart learning, multimedia

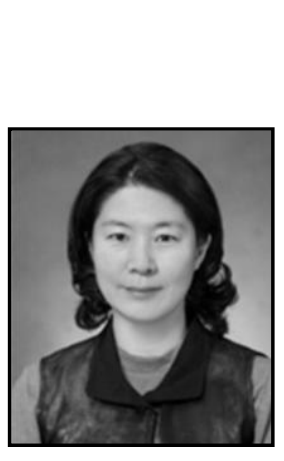
information retrieval. He is a member of the IEEE and the IEICE.

\section{Kyoung Hoon, Lew}

She is an Assistant Professor of Graduate School of Soongsil Univ. in Korea. She serves as a senior member under and a committee member of Korean Society for Creativity Education (KSCE) and The Korean Society for the Gifted \& Talented (KSGT). Her research interest includes Motivation, Creative environment, Program of creativity and Development of creativity etc. Until now, she wrote 30 papers, compiled a teaching book and perform project related with her field. 